\title{
Prospective Randomized Controlled Study Evaluating the Effect of Adding Dexamethasone to Bupivacaine on Adductor Canal Block Outcomes in Patients Undergoing Arthroscopic Anterior Cruciate Ligament Reconstruction
}

\author{
MOSTAFA A.A. EL-SAYED, M.Sc.; AMR A. MAGDY, M.D.; YASSER M. AMR, M.D. and \\ SALAH EL-DIN I. EL-SHERIF, M.D.
}

The Department of Anesthesiology and Surgical ICU, Faculty of Medicine, Tanta University, Tanta, Egypt

\begin{abstract}
Background: Adductor canal block is a new analgesic technique with fast functional recovery and good pain control, and it is predominantly a sensory block. Recent studies indicate that perineural dexamethasone increase the duration of peripheral nerve block analgesia.

Aim of Study: To evaluate the effect of adding dexamethasone to bupivacaine on the quality and duration of adductor canal block in patients undergoing arthroscopic anterior cruciate ligament reconstruction under general anaesthesia with visual analogue scale as primary outcome, total amount of morphine consumption and any reported side effects as secondary outcomes.
\end{abstract}

Material and Methods: Sixty adults (ages 18-60) scheduled for arthroscopic anterior cruciate ligament reconstruction under general anesthesia. Patients were classified into two equal groups each of 30 patients. Patients of group I received $15 \mathrm{ml} 0.5 \%$ bupivacaine plus perineural $2 \mathrm{ml}$ saline and patients of group II received $15 \mathrm{ml} 0.5 \%$ bupivacaine plus perineural dexamethasone $8 \mathrm{mg} / 2 \mathrm{~mL}$. pain scores, block duration, opioid consumption and time to first rescue analgesia were measured. Any undesirable side effects were recorded.

Results: In the present study, sensory block duration was prolongated in group II. In POD (postoperative day) 2 morphine consumption was less in group II. Time till first rescue analgesia was given was significantly shorter in group I than group II.

Conclusions: Adductor canal bock provides excellent analgesia after ACL reconstruction under general anaesthesia. Moreover, Dexamethasone when added to bupivacaine in adductor canal block is associated with significant prolongation of sensory block and significant decrease in total opioid consumption.

Correspondence to: Dr. Mostafa A.A. El-Sayed,

The Department of Anesthesiology and Surgical ICU, Faculty of Medicine, Tanta University, Tanta, Egypt
Key Words: Adductor canal block - Dexamethasone - Saphenous - ACL reconstruction.

\section{Introduction}

ANTERIOR cruciate ligament (ACL) tears remains a major injury in sports medicine, with an incidence of 68.6 per 100,000 person-years [1] Many patients reported having moderate to severe pain 24 hours after knee arthroscopy [2,3], and pain limited the patient's activity and decreased their satisfaction [2]. Which can delay rehabilitation and increase postoperative complications significantly.

Peripheral nerve blockade including femoral nerve block (FNB) and adductor canal block is known to provide outstanding postoperative analgesia after knee surgery with less hypotension compared with certain regimens of epidural analgesia [4] and avoids opioid related adverse effects. However, femoral nerve block decreases the motor power of the quadriceps muscle, which may increase the risk of postoperative falls and delay early postoperative mobilization, influencing patient satisfaction [5].

Adductor canal block is a newly progressing analgesic protocol and it is mainly a sensory block [6], which preserves quadriceps muscle power and ambulation ability better than femoral nerve block allowing for early mobilization and shorter hospital stay [5]

Adding dexamethasone to perineural local anesthetic injections may increase the duration and quality of peripheral nerve block analgesia [7] . 


\section{Patients and Methods}

This prospective randomized controlled study was carried out in Tanta University Hospital for six months from February 2016 to July 2016 on adult with physical status ASA I\&II classification scheduled for arthroscopic anterior cruciate ligament reconstruction under general anaesthesia. A written informed consent was obtained from all patients. Every patient received an explanation to the purpose of the study and had a secret code number and the photos applied only to the part of the body linked to the research to ensure privacy to participants and confidentiality of data. Research results only used for scientific purposes. Procedures were approved by both the institutional and the regional ethical committees. Inclusion criteria were: sixty patients, aged between 18 and 60 years, ASA I\&II, scheduled for arthroscopic anterior cruciate ligament reconstruction under general anaesthesia.

Exclusion criteria: Were general contraindication to regional nerve block like local infection or anatomic malformation at the site of the block, History of allergy to local Anaesthetics (amides) and Patients with coagulopathies, Patients with a history of seizures, known severe systemic diseases (Kidney, liver, respiratory, cardiac) and any neurological deficit in lower limb.

Patients were randomly classified using sealed envelope technique into two equal groups each of 30 patients. Group I control C received $15 \mathrm{ml} 0.5 \%$ bupivacaine plus perineural $2 \mathrm{ml}$ saline administered within approximately two minutes. Group II dexamethasone $\mathrm{D}$ received $15 \mathrm{ml} 0.5 \%$ bupivacaine plus perineural dexamethasone $8 \mathrm{mg} / 2 \mathrm{~mL}$ administered within approximately two minutes.

After completing fasting hours, General anesthesia was induced with propofol $2 \mathrm{mg} / \mathrm{kg}$ and fentanyl $1 \mathrm{r} / \mathrm{k}$. Tracheal intubation was facilitated by administration of cis-atracurium $0.1 \mathrm{mg} / \mathrm{kg}$. Anesthesia was maintained with isoflurane 1.2 MAC, cis-atracurium $0.02 \mathrm{mg} / \mathrm{kg}$ every 30 minutes and fentanyl $1 \mathrm{~g} / \mathrm{k}$ every hour as bolus dose. Routine standard monitoring was performed. The leg that underwent surgery was externally rotated, the knee slightly flexed, and the thigh prepared with betadine. The medial aspect of the thigh was scanned in a transverse axial plane using a highfrequency linear probe prepared in a sterile fashion. The probe was placed to obtain a short axis view of the femoral artery at the mid-femoral level. The saphenous nerve (SN) adjacent to the femoral artery was identified. The femoral artery was followed distally to the point at which it deviates posteriorly into the popliteal fossa. At this point, the saphenous nerve was identified as it continued in its original course just underneath the sartorius muscle. At a distance of no more than $7 \mathrm{~cm}$ proximal to the medial condyle, a short axis view of the sartorius and vastus medialis muscles was obtained with the saphenous nerve identified between the two muscles.

22 gauge spinal needle was advanced in plane with the ultrasound beam under real-time ultrasound guidance (in either a medial-to-lateral or a lateralto-medial orientation) toward the target nerve. Thereafter, $15 \mathrm{ml} 0.5 \%$ bupivacaine plus (perineural $2 \mathrm{ml}$ saline in group $\mathrm{C}$ or $2 \mathrm{ml}$ dexamethasone in group D) was injected around the SN. No further local anesthetics were injected into the knee joint or the site of harvested graft. Tourniquet was applied 5 minutes after the block.

Measurements: After recovery of general anesthesia block duration was estimated as the number of hours it took for patients to regain sensation in the medial aspect of the leg. Postoperative pain was assisted by the visual analogue scale (VAS; 0 no pain while 10 is the maximum pain) at $0,2,4,6$ then every 6 hours for 24 hours. Pain severity score 4 or more, was treated with morphine increment (2mg IV). VAS was measured at rest and during activity (the individual had to get up from a chair, walk $3 \mathrm{~m}$, turn, walk back to the chair, and sit down). Total morphine consumption at 24 hours after surgery, and time till administration of first rescue analgesia was recorded. However, during application of the study it was noted that block duration was extended beyond 24 hours in group II so total morphine consumption was recorded at 48 hours postoperative. Quadriceps muscle power; we asked the patients (in the supine position) to perform a straight leg raise. The motor block was graded as follows: $0=$ normal muscle power, $1=$ motor weakness, $2=$ complete motor paralysis. Any undesirable side effects during the first 24 hours was recorded (nausea - vomiting pruritis - Manifestations of local Anaesthetic toxicity: Bradycardia, Convulsions, Respiratory depression).

The sample size calculation is performed using EpI-Info 2002 software statistical package designed by World Health Organization (WHO) and by Centers for Disease Control and Prevention (CDC). The sample size is 30 per group based on the following considerations: $95 \%$ confidence limit, 
$80 \%$ power of the study and $1: 1$ for each study group.

Statistical presentation and analysis was conducted by SPSS V.24. Results were expressed as means \pm standard deviation (SD). Student paired $t$-test: For statistical analysis within the same group. Unpaired T test: used for comparison of parametric data (age, weight, HR and MAP). Modified chisquare test for small numbers: For comparison between three groups as regards qualitative data (sex). ANOVA test was used for comparison among different times in the same group in quantitative data. $p$-value $<0.05$ was considered significant.

\section{Results}

Regarding the demographic data (Table 1) as age, sex and weight, duration of surgery and tourniquet time there was no significant difference between both groups ( $p$-value $>0.05$ ).

The primary outcome, block duration grade 2 was more prolonged in group II with $p$-value $\left(<0.05^{*}\right)$ as shown in Fig. (1). In group I block duration ranged from 18.7 to 28.5 hours with a mean value $(24.73 \pm 2.43)$ and in group II block duration ranged from 24.2 to 37 hours with a mean value $(31.55 \pm 3.23)$.

Regarding secondary outcomes, visual analogue score (VAS) changes in both groups at rest, there was significant elevation in group I at $12 \mathrm{~h}, 18 \mathrm{~h}$, 24 h postoperatively ( $p$-value $<0.05^{*}$ ) as shown in Fig. (2). During activity, there was very significant elevation in group I at $12 \mathrm{~h}, 18 \mathrm{~h}, 24 \mathrm{~h}$ postoperatively $\left(p\right.$-value $\left.<0.05^{*}\right)$ as shown in Fig. (3).

The difference in POD 1 cumulative morphine consumption between the two groups was statistically insignificant with ( $p$-value 0.516$)$. In POD 1 cumulative morphine consumption in group I ranged from $0 \& 16$ with a mean value $4 \pm 4.72$ and in group II cumulative morphine consumption ranged from $0 \& 16$ with a mean value $3.2 \pm 4.76$. In POD 2 there was significant difference with less morphine consumption in group II ( $p$-value $<0.05^{*}$ ) In POD 2 cumulative morphine consumption in group I ranged from $0 \& 10$ with a mean value 2.33 \pm 3.14 and in group II cumulative morphine consumption ranged from $0 \& 6$ with a mean value 0.6 \pm 1.67 . as shown in Fig. (4).

In group I time to first rescue analgesia ranged from 20 to 185 minutes with a mean value $(98.87 \pm 4$ 0.17 ) and in group II time ranged from 75 to 240 minutes with a mean value $(123.17 \pm 39.77)$. It was more prolonged in group II $\left(p\right.$-value $\left.<0.05^{*}\right)$ as shown in Fig. (5).

No significant difference in both groups regarding post-operative complications ( $p$-value $>0.05$ ) as shown in Table (2).

Table (1): Demographic data, duration of surgery and tourniquet time in both groups.

\begin{tabular}{|c|c|c|c|}
\hline & Group I & Group II & $\begin{array}{c}p- \\
\text { value }\end{array}$ \\
\hline Age (years) & $28.67 \pm 7.74$ & $27.9 \pm 7.17$ & 0.692 \\
\hline Weight & $73.83 \pm 8.27$ & $77.27 \pm 8.8$ & 0.125 \\
\hline $\operatorname{Sex}(M / F)$ & $26 / 4$ & $27 / 3$ & 0.688 \\
\hline Duration of surgery (min) & $141 \pm 7.45$ & $139.8 \pm 12.47$ & 0.653 \\
\hline Tourniquet time (min) & $57.33 \pm 10.64$ & $58.03 \pm 9.62$ & 0.79 \\
\hline \multicolumn{4}{|c|}{ * Data presented as mean \pm SD. } \\
\hline \multicolumn{4}{|c|}{ Table (2): Complications in both groups. } \\
\hline \multirow{2}{*}{ Complication } & Group I & \multicolumn{2}{|c|}{ Group II } \\
\hline & $\%$ & $\mathrm{~N}$ & $\%$ \\
\hline PONV & 10.0 & 0 & 0.0 \\
\hline Drowsiness & 6.67 & 0 & 0.0 \\
\hline Total complication & 16.67 & 0 & 0.0 \\
\hline$p$-value & \multicolumn{3}{|c|}{0.0617} \\
\hline
\end{tabular}

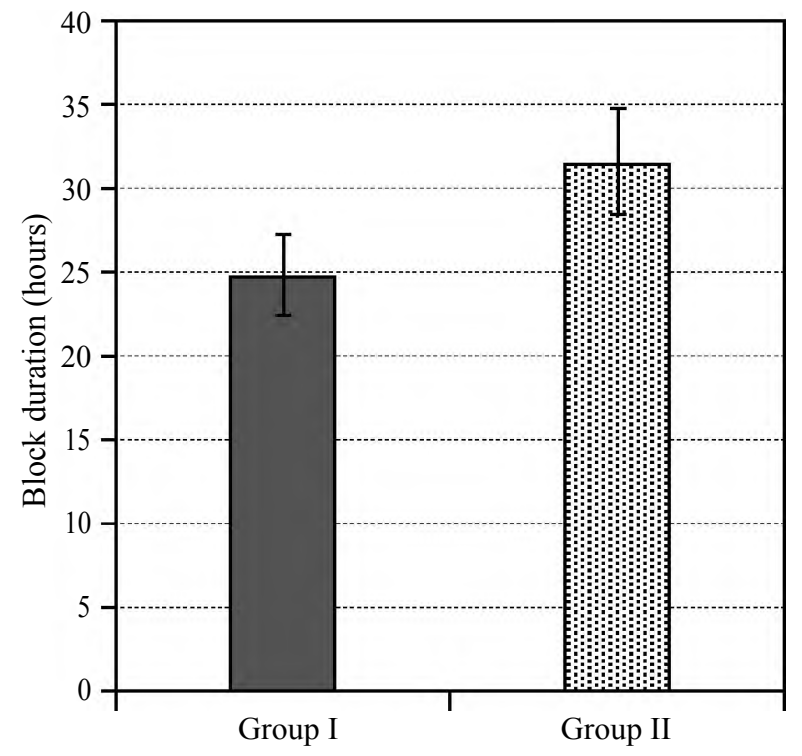

Fig. (1): Block duration in both groups/hours. 


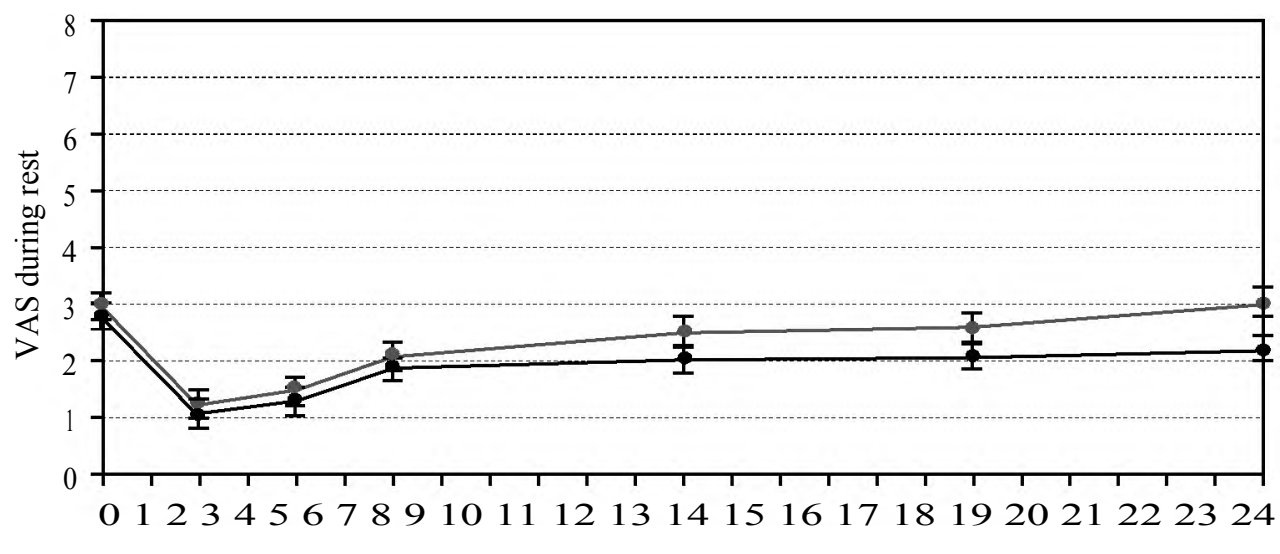

Time (hours)

\section{$\longrightarrow$ Group I $\longrightarrow$ Group II}

Fig. (2): Visual analogue score (VAS) in both groups during rest.
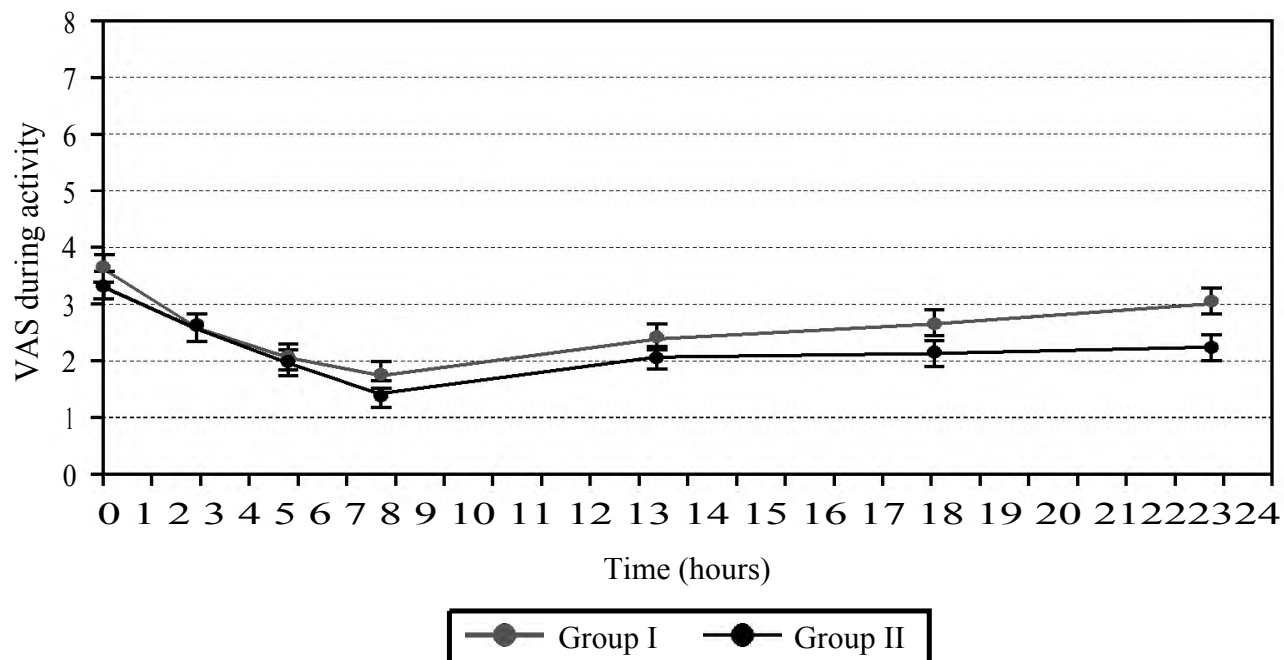

Fig. (3): Visual analogue score (VAS) in both groups during activity.

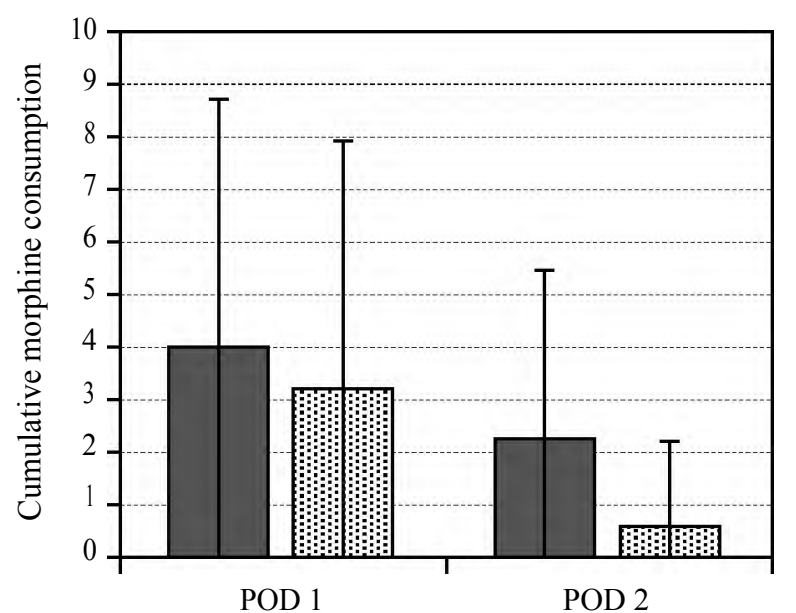

Group I 罒 Group II

Fig. (4): Cumulative morphine consumption in 48 hours

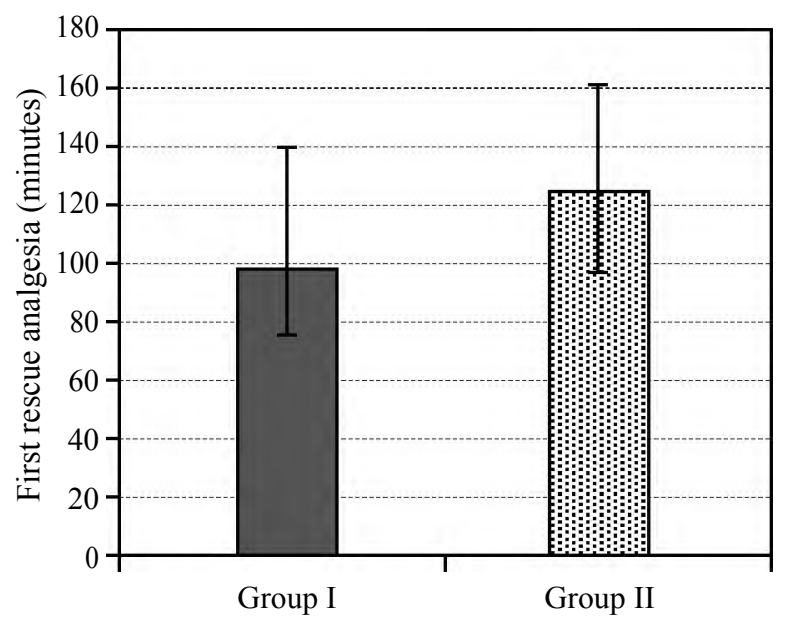

Group I

Fig. (5): Time to first rescue analgesia in both groups. 


\section{Discussion}

Adductor canal block (ACB) is a relatively new alternative providing pure sensory blockade with minimal effect on quadriceps strength. The adductor canal involves the vastus medialis nerve, medial femoral cutaneous nerve, articular branches from the obturator nerve, as well as the medial retinacular nerve in addition to saphenous nerve that innervate the medial, lateral, and anterior aspects of the knee $[8,9]$. In theory, ACB is almost a pure sensory nerve block, which only influences the motor function of vastus medialis due to its impact on nerve to the muscle as it traverses the adductor canal [10], preserving quadriceps muscle power.

Dexamethasone acts by possible attenuation of the small, unmyelinated, slow conducting $\mathrm{C}$ fiber responses in a dose-dependent manner leading to increased duration of selective sensory blockade and thus prolongation of peripheral nerve blockade. Other theories for its mechanism of action include anti-inflammatory or immune suppressive actions [11]. It is also speculated that along with local effects, the systemic effects of steroids may play a role in its prolonged analgesia [12].

This study revealed that addition of $8 \mathrm{mg} / 2 \mathrm{~mL}$ dexamethasone to $15 \mathrm{ml} 0.5 \%$ bupivacaine in adductor canal block results in a significant increase in duration of sensory blockade.

Concerning analgesia, both groups showed significant pain relief and patient satisfaction up to 24 hours postoperatively, however results showed a significant difference as regard the changes in the visual analogue pain score at rest and during activity at 12,18 , and 24 hours postoperatively between both groups with lower VAS scores with decreased need for rescue analgesia in group II. Comparison between both groups regarding to cumulative morphine consumption found that there was no significant difference between both groups during POD 1 while it showed significant difference in POD 2 with more consumption in group I.

In this study, results demonstrated no significant difference in both groups regarding to postoperative complications nevertheless, in group I three patients had postoperative nausea and two patients suffered drowsiness. The incidence of PONV in our study population was infrequent. The antiemetic property of propofol used for induction of anesthesia in our study may have contributed to this low incidence. however, decreased rates of PONV were noted when dexamethasone was used in TAP blocks for hysterectomy [13] .
There is no clinical evidence that $8 \mathrm{mg}$ perineural dexamethasone has any neurotoxic effects however further studies are needed prior to recommending routine use [14].

In agreement with our study, Abdallah et al. [1s found that ACB provides similar analgesia up to $24 \mathrm{~h}$ postoperatively and preserves quadriceps muscle strength when compared with FNB in patients undergoing ACL reconstruction.

In a recent review on adductor canal block for knee surgical procedures Vora et al. [16] concluded that $\mathrm{ACB}$ provides equivalent analgesia to $\mathrm{FNB}$ for primary total knee arthroplasty with the added advantage of less quadriceps weakness, early ambulation, and a trend toward earlier discharge. It can also be used as a rescue block in patients with moderate to severe pain after minor arthroscopic knee procedures.

Although, there was a lack of literature evaluating the role of dexamethasone as local anaesthetic adjuvant in adductor canal block. Our study is in agreement with Chisholm et al. [17] the only study to our knowledge that discussed the role of dexamethasone as perineural adjuvant with subsartorial saphenous nerve blocks in ACL reconstruction who revealed that adding dexamethasone $1 \mathrm{mg}$ and $4 \mathrm{mg}$ to local anaesthesia significantly prolongs subsartorial saphenous nerve duration.

Also, Bjørn et al. [18] noticed that adding $4 \mathrm{mg}$ dexamethasone to $10-\mathrm{mL} 0.5 \%$ bupivacaine with $1: 200,000$ epinephrine in subsartorial saphenous nerve blocks for analgesia after major ankle surgery was associated with significant prolongation of sensory block and significant decrease in total opioid consumption.

In agreement with our study, Sherif et al. [19] who studied the effect of dexamethasone as adjuvant for femoral nerve block following knee arthroplasty found that 8 milligrams of dexamethasone added to $0.5 \%$ bupivacaine followed by a continuous infusion prolonged the duration of analgesia provided by femoral nerve blockade by about $7 \mathrm{~h}(25.7 \pm 3 \mathrm{~h}$, vs $18.8 \pm 4 \mathrm{~h})$ with a reduction in opioid requirements.

In a recent systematic review of 14 studies involving 1022 patients, Knezevic et al. [20] came to the conclusion that the addition of dexamethasone to a brachial plexus block significantly reduced opioid consumption at $24 \mathrm{~h}$ and significantly improved postoperative pain scores at $48 \mathrm{~h}$ with no increase in complication rates. However, perineural adjuvant dexamethasone delayed the onset of sen- 
sory and motor block and prolonged the duration of motor block.

In contrast to our results, Cummings et al. [21] in a study evaluating effect of dexamethasone on the duration of interscalene nerve blocks with ropivacaine or bupivacaine demonstrated that perineural dexamethasone prolonged analgesia duration, but it did not decrease postoperative opioid consumption over the first $72 \mathrm{~h}$. There are likely several reasons for this. First, cumulative $72 \mathrm{~h}$ consumption is too long a time frame over which to expect differences in opioid consumption, particularly when the duration of analgesia does not last that long. Secondly, varying analgesic protocols likely influenced opioid consumption.

\section{Conclusions:}

Adductor canal bock provides excellent analgesia after ACL reconstruction under general anaesthesia. Moreover, Dexamethasone when added to bupivacaine in adductor canal block is associated with significant prolongation of sensory block and significant decrease in total opioid consumption.

\section{Acknowledgments:}

This research was carried out without funding.

\section{Conflicts of interest:}

No conflicts of interest declared.

\section{Authors' contributions:}

All authors had equal role in design, work, statistical analysis and manuscript writing.

\section{References}

1- SANDERS T.L., KREMERS H.M., BRYAN A.J., LARSON D.R., DAHM D.L., LEVY B.A., et al.: Incidence of Anterior Cruciate Ligament Tears and Reconstruction A 21-Year Population-Based Study. The American Journal of Sports Medicine, 44 (6): 1502-7, 2016.

2- McGRATH B., ELGENDY H., CHUNG F., KAMMING D., CURTI B. and KING S.: Thirty percent of patients have moderate to severe pain $24 \mathrm{hr}$ after ambulatory surgery: A survey of 5,703 patients. Canadian Journal of Anesthesia, 51 (9): 886-91, 2004

3- PAVLIN D.J., CHEN C., PENALOZA D.A. and BUCKLEY F.P.: A survey of pain and other symptoms that affect the recovery process after discharge from an ambulatory surgery unit. J. Clin. Anesth., 16 (3): 200-6, 2004.

4- FOWLER S., SYMONS J., SABATO S. and MYLES P.: Epidural analgesia compared with peripheral nerve blockade after major knee surgery: A systematic review and meta-analysis of randomized trials. Br. J. Anaesth., 100 (2): 154-64, 2008.

5- JÆGER P., NIELSEN Z.J., HENNINGSEN M.H., HILSTED K.L., MATHIESEN O. and DAHL J.B.: Adductor Canal Block versus Femoral Nerve Block and Quadriceps
StrengthA Randomized, Double-blind, Placebo-controlled, Crossover Study in Healthy Volunteers. The Journal of the American Society of Anesthesiologists, 118 (2): 409$15,2013$.

6- LUND J., JENSTRUP M., JAEGER P., SØRENSEN A and DAHL J.: Continuous adductor-canal-blockade for adjuvant post-operative analgesia after major knee surgery: Preliminary results. Acta. Anaesthesiol. Scand., 55 (1): 14-9, 2011.

7- CUMMINGS K.C., NAPIERKOWSKI D., PARRASANCHEZ I., KURZ A., DALTON J., BREMS J., et al.: Effect of dexamethasone on the duration of interscalene nerve blocks with ropivacaine or bupivacaine. Br. J. Anaesth., aer159, 2011.

8- KIM D.H., LIN Y., GOYTIZOLO E.A., KAHN R.L., MAALOUF D.B., MANOHAR A., et al.: Adductor Canal Block versus Femoral Nerve Block for Total Knee Arthroplasty A Prospective, Randomized, Controlled Trial. The Journal of the American Society of Anesthesiologists., 120 (3): 540-50, 2014

9- JÆGER P., ZARIC D., FOMSGAARD J.S., HILSTED K.L., BJERREGAARD J., GYRN J., et al.: Adductor canal block versus femoral nerve block for analgesia after total knee arthroplasty: A randomized, double-blind study. Reg. Anesth. Pain Med., 38 (6): 526-32, 2013.

10- SHAH N.A. and JAIN N.P.: Is continuous adductor canal block better than continuous femoral nerve block after total knee arthroplasty? Effect on ambulation ability, early functional recovery and pain control: A randomized controlled trial. The Journal of Arthroplasty, 29 (11): 2224-9, 2014

11- KOYYALAMUDI V., SEN S., PATIL S., CREEL J.B., CORNETT E.M., FOX C.J., et al.: Adjuvant Agents in Regional Anesthesia in the Ambulatory Setting. Current Pain and Headache Reports, 21 (1): 6, 2017.

12- ABDALLAH F.W., JOHNSON J., CHAN V., MURGATROYD H., GHAFARI M., AMI N., et al.: Intravenous dexamethasone and perineural dexamethasone similarly prolong the duration of analgesia after supraclavicular brachial plexus block: a randomized, triple-arm, doubleblind, placebo-controlled trial. Reg. Anesth. Pain Med., 40 (2): 125-32, 2015

13- AMMAR A.S. and MAHMOUD K.M.: Effect of adding dexamethasone to bupivacaine on transversus abdominis plane block for abdominal hysterectomy: A prospective randomized controlled trial. Saudi Journal of Anaesthesia., 6 (3): 229, 2012.

14- NOSS C., MacKENZIE L. and KOSTASH M.: Dexamethasone a promising adjuvant in brachial plexus anesthesia? A systematic review. J. Anesth. Clin. Res., 5 (7): 1000421, 2014.

15- ABDALLAH F.W., WHELAN D.B., CHAN V.W., PRASAD G.A., ENDERSBY R.V., THEODOROPOLOUS J., et al.: Adductor Canal Block Provides Noninferior Analgesia and Superior Quadriceps Strength Compared with Femoral Nerve Block in Anterior Cruciate Ligament Reconstruction. Anesthesiology, 124 (5): 1053-64, 2016.

16- VORA M.U., NICHOLAS T.A., KASSEL C.A. and GRANT S.A.: Adductor canal block for knee surgical procedures: Review article. J. Clin. Anesth., 35: 295-303, 2016. 
17- CHISHOLM M.F., CHENG J., FIELDS K.G., MARX R.G., MAALOUF D.B., LIGUORI G.A., et al.: Perineural dexamethasone with subsartorial saphenous nerve blocks in ACL reconstruction. Knee Surg. Sports Traumatol. Arthrosc., 1-9, 2016.

18- BJØRN S., LINDE F., NIELSEN K.K., BØRGLUM J., HAURITZ R.W. and BENDTSEN T.F.: Effect of Perineural Dexamethasone on the Duration of Single Injection Saphenous Nerve Block for Analgesia After Major Ankle Surgery: A Randomized, Controlled Study. Reg. Anesth. Pain Med., 2017.

19-SHERIF A. and ELSERSY H.: Dexamethasone as adjuvant for femoral nerve block following knee arthroplasty: A randomized, controlled study. Acta. Anaesthesiol. Scand., 60 (7): 977-87, 2016

20- KNEZEVIC N.N., ANANTAMONGKOL U. and CANDIDO K.D.: Perineural dexamethasone added to local anesthesia for brachial plexus block improves pain but delays block onset and motor blockade recovery, 2015.

21- CUMMINGS K.C., 3rd, NAPIERKOWSKI D.E., PARRASANCHEZ I., KURZ A., DALTON J.E., BREMS J.J., et al.: Effect of dexamethasone on the duration of interscalene nerve blocks with ropivacaine or bupivacaine. Br. J. Anaesth., 107 (3): 446-53, 2011.

\section{دراسة مستقبلية عشوائية محكمة لتقييم أثر إضافة الديكساميثازون إلى البيوبيفاكين

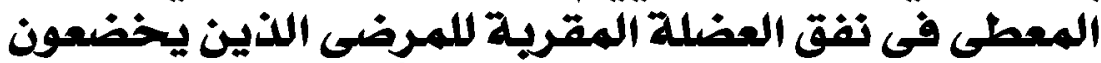 لعملية إعادة بناء الرياط المتصالب الأمامى بواسطة المقائر المنظار}

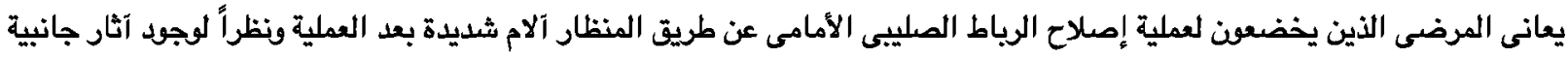

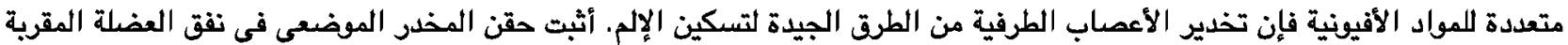

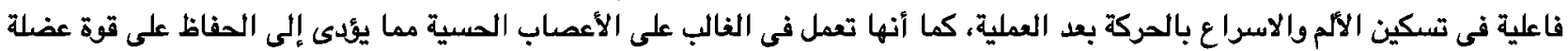

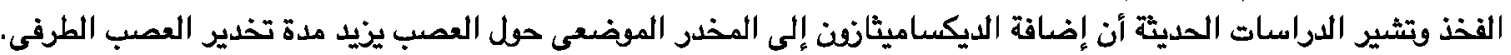

الهدف من هذه الدراسة هو تقييم أثر إضافة الديكساميثانفن إلى البيوبيفاكين المعطى فى نفق العضلة المقربة للذين يخضعون لعملية

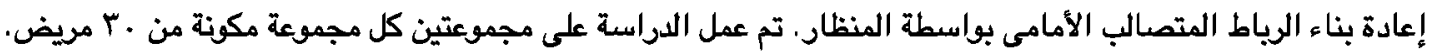

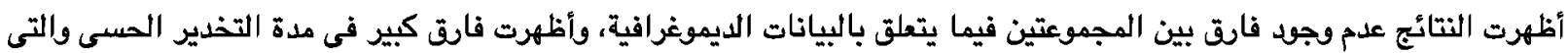

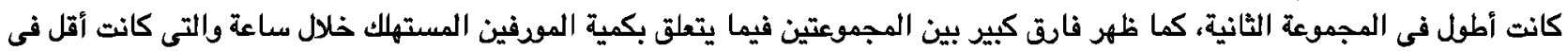

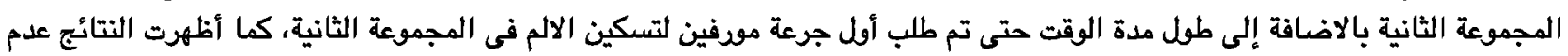

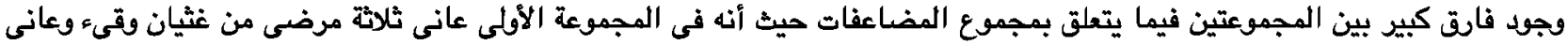
مريضان من النعاس. 